\title{
Erratum
}

Commun. Math. Phys. 132, 3-4 (1990)

We apologize for an unfortunate omission in the tribute "To Arthur Wightman." The location line, "Rigi, January 1990," was inadvertently omitted. The complete text is reprinted here so that these pages can be substituted for the original ones when the volume is bound. 



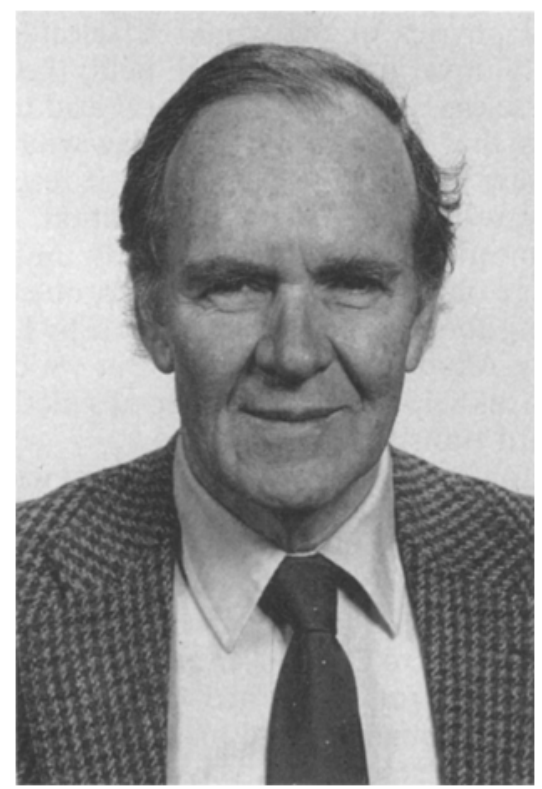

\section{To Arthur Wightman}

Disease and age enwrap my life as a permanent wintertime. A thick fog of oblivion covers my past. Chance rather than relevance determines what I remember. But unexpectedly the clouds disperse and free the view on a blue sky and massifs of inaccessible mountains, peaks on which in old times we oriented our work. Such a massif is Arthur Wightman's scientific work and teaching. I had the privilege to roam through some of its modest foothills.

I met Arthur and his wife Anna-Greta shortly after our arrival in the United States in December 1949 in the flat of our unforgettable friends Sonya and Valya Bargmann. I did not, at that time, realize to whom I had just been introduced. I was still ignorant of the wide difference in scientific standards between Zürich, where I came from, and Princeton. As an example, I barely knew the definition of a Hilbert space. (I had memorized the axioms from J. von Neumann's book on the Mathematical Foundations of Quantum Mechanics, a book which I had read despite the warnings of my teachers.) Arthur, however, moved with ease through the vast domains of functional analysis. During his student days he had been a member of a congregation, named "The Group Characters," which included the later mathematician John Tate. Together they studied the difficult modern theory of the unitary representation of non-compact groups, a theory to which Eugene Wigner and Valentine Bargmann had made so decisive initial contributions. No wonder then that our meeting at the Bargmann's did not, for the moment, result in a close connection between Arthur and myself. He was occupied by problems of principle in the domain of theoretical physics, whereas I played with peripheral trifles, paying little attention to the developments in the center of science. So it happened that the fundamental investigation of G.C. Wick, A.S. Wightman, and E.P. Wigner, which introduced the all important notion of superselection rules, was almost lost on me, as was the analysis of L. Gårding and A.S. Wightman on the representations of the canonical anticommutation and commutation relations. 
An incident which took place in Copenhagen in June 1952 illustrates the situation in theoretical physics of that time. A select group of theoreticians discussed relativistically invariant, non-local field theories. The variational principle applied to these cases does not in general lead to an energy integral. It was the accepted opinion that such a conservation law would not exist. Arthur was the lone fighter, who saw the truth and defended it resolutely: the invariances under time translation must imply energy conservation.

Copenhagen was a meeting place for physicists. In the same year 1952, Walter Kohn and I worked there on the inverse scattering problem. Through Arthur we learnt from Lars Gårding about an all-important note by I.M. Gel'fand and B.M. Levitan in the Doklady Akad. Nauk. S.S.S.R. But we did not know Russian. Arthur rescued us. With his help and with the help of a dictionary we finally pieced together a word by word translation.

In 1955 I left Princeton for Zürich. My next contact with Arthur was indirect. It was in fall 1956. On my way back from the U.S. I stopped over in Göttingen, where I met with R. Haag, H. Lehmann, K. Symanzik, and W. Zimmermann. In a discussion I discovered a mistake in a preprint by Gunnar Källén on the threepoint function in field theory. With great restraint (so it seemed to me) I communicated my observation to Gunnar - and obtained a most indignant reply, in which he defended his error. It turned out that Arthur was visiting in Copenhagen, and Gunnar thought he had his support. It matters little how the misunderstanding finally was resolved. It was only important that my ties with Arthur became strengthened. On March $29^{\text {th }} 1957$ he and Anna-Greta visited us in Bern. While the ladies toured the city, Arthur and I worked in front of a blackboard in my old Gymnasium: he explained to me his field theory. That was my initiation. In the early morning of the next day my second son Beat was born.

Res Jost

Rigi, January 1990 